\title{
Alireza Askari Chaverdi, Pierfrancesco Callieri. "Tol-e Ajori and Takht-e Jamshid: a Sequence of Imperial Projects in the Persepolis Area"
}

\section{Sébastien Gondet}

\section{(2) OpenEdition}

Journals

Édition électronique

URL : https://journals.openedition.org/abstractairanica/53582

DOI : 10.4000/abstractairanica.53582

ISSN : 1961-960X

Éditeur :

CNRS (UMR 7528 Mondes iraniens et indiens), Éditions de l'IFRI

Référence électronique

Sébastien Gondet, «Alireza Askari Chaverdi, Pierfrancesco Callieri. "Tol-e Ajori and Takht-e Jamshid: a Sequence of Imperial Projects in the Persepolis Area" », Abstracta Iranica [En ligne], Volume 42-43 | 2021, document 73, mis en ligne le 30 décembre 2021, consulté le 13 décembre 2022. URL : http:// journals.openedition.org/abstractairanica/53582 ; DOI : https://doi.org/10.4000/abstractairanica. 53582

Ce document a été généré automatiquement le 13 décembre 2022.

Tous droits réservés 


\title{
Alireza Askari Chaverdi, Pierfrancesco Callieri. “Tol-e Ajori and Takht-e Jamshid: a Sequence of Imperial Projects in the Persepolis Area"
}

\author{
Sébastien Gondet
}

\section{RÉFÉRENCE}

Alireza Askari Chaverdi, Pierfrancesco Callieri, “Tol-e Ajori and Takht-e Jamshid: a Sequence of Imperial Projects in the Persepolis Area", East and West, n.s. 1(1), 2020, p. 177-204.

1 En introduction de ce compte-rendu, il faut tout d'abord saluer ici la relance, sous l'impulsion de l'ISMEO - Associazione Internazionale di Studi sul Mediterraneo e l'Oriente basée à Rome, de la publication du journal East and West interrompue depuis plus de 10 ans. Les articles qui nourrissent le premier numéro de la nouvelle série de ce journal ont été rédigés par plusieurs collègues italiens et leurs partenaires investis dans des projets de recherche en cours, essentiellement en archéologie. East and West reprend donc en partie sa ligne éditoriale traditionnelle qui est d'être le vecteur privilégié de diffusion en anglais des résultats de la très active recherche italienne sur l'Orient et plus largement sur l'Asie.

2 On trouvera donc dans ce numéro cet article traitant des résultats obtenus par la mission irano-italienne à Persépolis, en activité depuis 2008, et signé par ses deux codirecteurs. Il propose une synthèse des principaux résultats obtenus au cours des différentes campagnes de terrain, intégrant sondages et fouilles archéologiques ainsi que prospections, conduites à l'ouest de la Terrasse de Persépolis depuis 2008. Cette 
revue permet également aux A. de détailler les évolutions et les corrections apportées, au fur et à mesure de leurs recherches, à la restitution de la ville - ou de l'agglomération, pour utiliser un terme moins connoté - qui devait exister à côté et en relation avec l'ensemble monumental fondé sur et autour de la Terrasse à partir du règne de Darius aux alentours 520 av. n. è.

3 Si cet article n'expose aucune donnée nouvelle, il démontre néanmoins, suivant une démonstration bien articulée, toute la portée des résultats obtenus successivement au cours de ces quinze dernières années à Persépolis. Alors que leurs publications précédentes présentaient dans le détail les résultats des opérations archéologiques conduites d'abord à Persépolis Ouest (cf. le compte rendu dans Abstracta Iranica, vol. 40-41, R3-2-2, n 23), puis à Firuzi sur le site de Tol-e Ajori (cf. les compte rendu dans Abstracta Iranica: vol. 40-41, R3-2-2, $\mathrm{n}^{\circ} 6$ et vol. 37-38-39, R3-2-2, $\mathrm{n}^{\circ}$ 70), les A. proposent ici une interprétation d'ensemble des données obtenues afin de produire une proposition de restitution globale de l'organisation spatiale de Persépolis et surtout de son évolution au cours de la période achéménide.

Pour les A., l'histoire de Persépolis commence bien avant la construction du secteur royal de Darius et, très probablement, au cours du règne de Cyrus avec la construction d'un premier complexe monumental dans le secteur de Firuzi, situé à $3 \mathrm{~km}$ à l'ouest de la Terrasse. Cette chronologie repose en grande partie sur une discussion concernant la datation d'un des édifices de ce complexe mis au jour par l'équipe sur le site de Tol-e Ajori et dont l'architecture reprend celle de la porte d'Ishtar à Babylone. Plusieurs paragraphes sont consacrés à exposer dans le détail l'ensemble des éléments de datation rassemblés au cours des fouilles qui concordent à dater le bâtiment de Tol-e Ajori du tout début de la période achéménide. Ainsi la Humadēšu des textes babyloniens ou la Pārsa/Matezziš des textes élamites qui préexistait à la Terrasse devait donc s'étendre, au moins en partie, dans le secteur de Firuzi ainsi que d'autres archéologues l'avaient suggéré auparavant. Pour les périodes postérieures, à partir de Darius, les travaux irano-italiens ont contribué à confirmer que le centre de gravité de Persépolis se déplace en direction de la Terrasse à l'ouest de laquelle se développe une occupation peu dense et suivant une morphologie très diffuse qui perdurera encore bien après la période achéménide.

\section{AUTEURS}

\section{SÉBASTIEN GONDET}

UMR 5133 CNRS-Université de Lyon 